\title{
GRUPO DE PESQUISA A TEMÁTICA AMBIENTAL E O PROCESSO EDUCATIVO: CONCEPÇÕES E PRÁTICAS
}

\author{
Dalva Maria Bianchini Bonotto; Luciano Fernandes Silva; Luiz Carlos \\ Santana; Luiz Marcelo de Carvalho; Rosa Maria Feiteiro Cavalari ${ }^{1}$
}

Resumo: Neste texto procura-se apresentar um breve histórico do Grupo de Pesquisa A Temática Ambiental e o Processo Educativo, enfatizando-se os referenciais teórico-metodológicos que têm orientado as suas pesquisas e os objetivos mais gerais de suas investigações. O exercício de explicitar a forma como determinada sociedade "torna a natureza presente" é visto pelo grupo como de fundamental importância para compreendermos os modelos teóricos e as ações práticas relacionadas com processos educativos e a temática ambiental. Para o desenvolvimento de suas pesquisas o grupo procura mapear as tendências teóricas e metodológicas da educação ambiental em textos acadêmicos, em relatos de pesquisa e em propostas e projetos educativos, bem como caracterizar os sentidos atribuídos à temática ambiental, à relação sociedade-natureza, à Educação e à Educação Ambiental explorando as dimensões consideradas fundamentais para o processo educativo, a saber, epistemológica, axiológica e política.

Palavras-chave: temática ambiental; pesquisa em educação ambiental; grupos de pesquisa.

Abstract: This paper presents a summary of the history of the Environmental Themes and the Educational Process research group, emphasizing the theoretical and methodological frameworks that have guided its research activities and its general investigation objectives. The exercise of making explicit how a specific society "makes nature present" is seen by this group as a fundamental step to comprehend the theoretical models and action practices related to educational processes and environmental themes. To carry out its researches, this group try to map theoretical and methodological tendencies in academic texts, mainly in research reports and in educational proposals and projects, as well as to characterize the meanings given to environmental themes, to the relation between society and nature, and to education and environmental education, exploring the dimensions considered fundamental to the educational process, namely, the epistemological, axiological and political dimensions.

Key words: environmental issues; environmental education research; research group

${ }^{1}$ Docentes do Instituto de Biociências - Campus de Rio Claro da Universidade Estadual Paulista Júlio de Mesquita Filho. 


\section{Breve histórico do grupo}

O grupo de pesquisa "A Temática Ambiental e o Processo Educativo" iniciou suas atividades de forma sistemática no final de 1991 e início de 1992, vinculando os seus trabalhos a um projeto da Pró-reitoria de Graduação da UNESP denominado Núcleos de Ensino. Os Núcleos de Ensino foram propostos com o objetivo de possibilitar uma maior relação entre a Universidade e a Rede Pública de Ensino Fundamental e Médio.

Dentre os primeiros projetos de pesquisa propostos pelo grupo, dois deles, desenvolvidos no período de 1995 a 1997, merecem destaque. "A Temática Ambiental e a Produção de Material Didático: uma proposta interdisciplinar" e "Natureza e Ciência na Escola de Ensino Fundamental".

A partir das experiências adquiridas com esses projetos e com os demais vivenciados pelo Grupo de Pesquisa iniciamos, a partir de 1998, a elaboração de uma proposta de um Curso de Especialização - lato sensu. Desde o início das discussões da proposta e da elaboração do plano do curso, optamos pela pesquisa como a ação prática articuladora das questões trabalhadas pelas diferentes -disciplinas. $\mathrm{O}$ curso de especialização foi assim oferecido no ano de 2000, como uma das atividades do Grupo e com o apoio dos Departamentos de Educação, de Ecologia e de Educação Física da UNESP, Campus de Rio Claro.

O grupo está hoje vinculado ao Programa de Pós-Graduação em Educação, do Instituto de Biociências da UNESP, Campus de Rio Claro. Foram concluídas até a presente data vinte e uma dissertações de mestrado junto a esse Programa e outras dez estão em desenvolvimento. Cinco doutorados foram desenvolvidos junto ao Programa de Pós-Graduação em Educação Escolar UNESP - Araraquara sob orientação de docentes vinculados ao grupo de pesquisa e outros três estão em andamento.

No período de 2002 a 2003 o Grupo participou do "Programa de Cooperação entre a União Européia e América Latina (ALFA)", integrando o projeto idealizado pela "Rede Ambientalização Curricular dos Estudos Superiores (Rede ACES)". Participaram desse projeto outras Universidades do Estado de São Paulo como a Universidade Estadual de Campinas (UNICAMP) e a Universidade Federal de São Carlos (UFSCar) e da América Latina, Universidade de Cuba e Argentina, além de Universidades Européias - Espanha, Portugal, Itália e Alemanha.

O Grupo a partir do ano 2000 participou ativamente no processo de constituição do GT 22 - Educação Ambiental - junto a Associação Nacional de Pós-Graduação em Educação (ANPED). Em parceria com pesquisadores da Faculdade de Filosofia, Ciências e Letras de Ribeirão Preto / USP e da UFSCar, tem organizado os Encontros de Pesquisa em Educação Ambiental (EPEA). A última versão desse evento ocorreu em 2009, na UFSCar. Também em pareceria com as outras duas universidades anteriormente citadas, co-organizadoras do EPEA, o Grupo participa da equipe editorial do periódico "Pesquisa em Educação Ambiental" que conta atualmente com oito números editados. 


\section{Referencial teórico para o desenvolvimento dos projetos}

O reconhecimento, a construção e a caracterização por diferentes grupos sociais do que poderíamos chamar de "crise ambiental", em diferentes regiões do mundo, no final da década de 1960 e início dos anos de 1970, foram acompanhados de tentativas diversificadas de compreensão deste processo. Estas tentativas têm se constituído desde tarefas mais simples, embora extensas, como, por exemplo, a de identificação e mapeamento das diferentes situações de degradação ambiental, até o desenvolvimento de exercícios mais ousados de busca de modelos explicativos que nos permitam compreender as raízes dos atuais padrões de relação da sociedade com os demais elementos da natureza.

Paralelamente a estes exercícios de explicitação, compreensão e construção de significados sobre a temática ambiental seguem-se as tentativas de identificação de modelos de ação que possam fazer frente às tendências de destruição e de degradação do mundo natural no seu sentido mais amplo.

Observa-se que a busca de modelos de ação e a definição de medidas, por parte de certos setores sociais, com o objetivo de minimizar, corrigir ou reverter situações de impacto ambiental ou a busca de possíveis transformações radicais dos padrões de relação ser humano-sociedade-natureza têm apontado para caminhos bastante diversificados em termos de propostas de ação.

No entanto, é emblemático o fato de constatarmos hoje, nos diferentes setores sociais, uma forte tendência em reconhecer o processo educativo como uma possibilidade de provocar mudanças e alterar o atual quadro de degradação do ambiente com o qual deparamos. Independente do modelo adotado para explicar o atual estado de agressão à natureza, o processo educativo é sempre apresentado como uma possibilidade de alteração desse quadro, isto é como um agente eficaz de transformação.

O desenvolvimento de propostas educacionais relacionadas com a temática ambiental nos coloca diante de um duplo desafio que pode ser entendido como um trabalho de identificação de duas faces de uma mesma moeda, a saber: a necessidade de termos clareza quanto a nossas perspectivas tanto em relação ao processo educativo quanto em relação à temática ambiental.

Os exercícios, desenvolvidos nos últimos anos para responder a questões como essas, têm nos indicado que as concepções de natureza, de relação sociedade-natureza e de educação são alguns dos elementos chave que orientam o processo de construção de modelos teóricos e de ações práticas relacionados com a Educação Ambiental.

No que diz respeito à concepção de natureza e de relação sociedade natureza torna-se relevante procurar compreender de que maneira determinada sociedade, em determinada época histórica, concebe a natureza e a própria relação entre a sociedade e a natureza, bem como buscar identificar as concepções de educação veiculadas por meio da produção teórica da área e das propostas de ação. Neste sentido, parece-nos de fundamental importância considerar de forma cuidadosa as questões colocadas pelo movimento 
ambientalista, procurando compreender as implicações reais do discurso ecológico para os diferentes setores da atividade humana. Esta é a possibilidade que temos para fugir às interpretações ingênuas e aos riscos dos modismos, muitas vezes presentes entre nós.

$\mathrm{Na}$ tentativa de compreender a complexidade da questão ecológica, alguns autores, por exemplo, BORNHEIM, 1985; 2001 têm apontado que "a questão toda se concentra, portanto, no modo como a natureza se faz presente para o homem; ou melhor: o modo como o homem torna a natureza presente".

Assim sendo, a idéia de natureza não é algo "natural", e sim, cultural, ou seja, tal idéia é construída historicamente. Cada sociedade, de acordo com a sua cultura e com suas condições materiais de existência, constrói, elabora uma idéia de natureza. As concepções que essa sociedade tem de natureza serão determinantes nas relações que com ela serão estabelecidas.

Nesse sentido, explicitar a forma como determinada sociedade "torna a natureza presente" é de fundamental importância para compreendermos os modelos teóricos e de ações práticas relacionadas com processos educativos que, pelo menos no nível da intenção buscam a superação dos impasses gerados pela problemática ambiental.

Em relação a este aspecto têm se mostrado extremamente profícuas as reflexões empreendidas pela "Teoria Crítica", particularmente as realizadas por Adorno e Horkheimer (1985), quando apontam que como conseqüência do bem sucedido projeto do esclarecimento "[...] o que os homens querem aprender da natureza é como empregá-la para dominar completamente a ela e aos homens". p. 20.

Ainda como tentativa de compreender a complexidade das questões relativas à natureza e as relações sociedade-natureza outro referencial teórico tem sido adotado pelo Grupo, a saber, as instigantes reflexões empreendidas por Bruno Latour em sua proposta de "politizar" a natureza, ou seja, evidenciar os entrelaçamentos entre a política e a natureza (LATOUR, 2004).

Assim como diferentes visões de natureza ou de modelos de relação sociedade - natureza definem diferentes propostas teóricas ou programas de ações em educação ambiental, as diferentes dimensões do processo educativo enfatizadas em tais propostas são também elementos-chave nas tentativas de mapeamento e explicitação de concepções de educação ambiental.

Desse modo, na tentativa de identificarmos algumas das possíveis dimensões que poderiam ser consideradas nesse processo de reciprocidade, temos procurado, com o intuito de oferecer algumas orientações tanto para a construção e desenvolvimento de nossos projetos de ação como para o desenvolvimento de nossas investigações em educação ambiental, explorar três dimensões que nos parecem fundamentais nas discussões sobre a temática ambiental e sobre o processo educativo, quais sejam: 
- Dimensão relacionada à natureza dos conhecimentos.

- Dimensão axiológica de nossa existência, isto é, relacionada com os valores éticos e estéticos.

- Dimensão política, central na caracterização do processo educativo em geral e para os processos de educação ambiental em particular.

É importante destacar que esse modelo considera a dimensão política como central na caracterização do processo educativo em geral e para os processos de educação ambiental em particular. As outras duas dimensões explicitadas são compreendidas como dimensões de complementaridade e de reciprocidade relativa à dimensão política. É nesta relação intrínseca entre conhecimento, valores e a dimensão política que se busca compreender a temática ambiental e as relações entre sociedade e natureza (LEFF, 2002; LATOUR, 2004; GIACOIA, 2007)

São estas diferentes dimensões da existência humana que sustentam a possibilidade de intencionalização de nossas ações, visando à formação de seres humanos. A dimensão política da Educação que se concretiza pela práxis humana, por meio da participação coletiva dos indivíduos na construção do ideal de cidadania e de uma sociedade democrática, desvenda o caráter contraditório e dialético do processo educativo (CURY, 1985; SEVERINO, 2001). A prática humana intencionalizada, e dentre estas a prática educativa, nos coloca frente à necessidade de sinalizar as direções que pretendemos imprimir às possíveis transformações dela decorrentes.

Os diferentes projetos de pesquisa que vêm sendo desenvolvidos pelo grupo pretendem identificar as concepções de Educação Ambiental veiculadas tanto em propostas de educação ambiental como em práticas educativas realizadas em contextos diversos, assim como na produção teórica e de pesquisa na área. Nas análises realizadas pelos diversos projetos procuramos focalizar a própria concepção de educação, de natureza e de relação sociedade-natureza veiculada tanto nos textos acadêmicos como nos projetos de ação de educação ambiental, bem como identificar, as diferentes dimensões - dos conhecimentos, dos valores e da participação política - consideradas em tais propostas práticas e nas produções textuais.

Que pressupostos são eleitos para orientar as nossas reflexões, para ancorar as nossas simbolizações ou que justificam as nossas decisões políticas frente à temática ambiental e ao processo educativo? Que dimensões da existência humana têm sido consideradas tanto em projetos que relacionam o processo educativo com a temática ambiental como na produção teórica nesta área? Que concepções e práticas têm sido enfatizadas na produção teórica e nos processos educacionais que envolvem a temática ambiental? Que são os elementos chave no processo de construção ou de elaboração de sentidos, dos discursos e das práticas de educação ambiental?

Espera-se, assim, que as análises empreendidas bem como as tentativas de respostas a questões dessa natureza possam contribuir para o debate acerca 
das reflexões sobre aspectos teórico-metodológicos das propostas relacionadas com educação ambiental presentes tanto em projetos de ação como nos trabalhos acadêmicos produzidos no Brasil.

Se de um lado, as questões acima explicitadas podem ser exploradas a partir das perspectivas que a "análise de conteúdo" nos apresenta, de outro, perspectivas hoje apresentadas pelas "análises de processos de construção de sentidos", nos permitem explorar outro conjunto de questões, a saber: que sentidos têm sido construídos nas práticas curriculares sobre "educação ambiental" no contexto da escola básica? Que sentidos têm sido produzidos pelos professores que desenvolvem atividades de educação ambiental? Que sentidos têm sido produzidos em cursos de formação inicial e contínua de professores quando do desenvolvimento de práticas de educação ambiental? Que sentidos têm sido construídos pelos pesquisadores que têm centrado suas investigações em aspectos diversos da incorporação da temática ambiental pela escola básica?

\section{Objetivos}

Considerando tais questões como orientadoras dos diferentes projetos de pesquisa vinculados a essa proposta, o objetivo em uma perspectiva mais ampla do Grupo é o de fazer um mapeamento das tendências e perspectivas da educação ambiental presentes em textos acadêmicos, de produção de pesquisa e em propostas de práticas educativas relacionadas com a temática ambiental. Nesta direção, temos procurado identificar e caracterizar as concepções de Educação Ambiental presentes tanto nas práticas pedagógicas relacionadas com a temática ambiental e desenvolvidas em diferentes contextos educacionais quanto na produção teórica referente a educação ambiental. Em um segundo nível de aprofundamento dos projetos, buscamos caracterizar processos de produção de sentidos sobre temática ambiental e sobre processos educacionais.

Assim, para a concretização deste objetivo procuramos nos diferentes projetos de pesquisa que se vinculam a essa proposta, identificar a concepção de educação, de natureza e de relação sociedade-natureza, e as diferentes dimensões - dos conhecimentos, dos valores e da participação política - presentes em diferentes propostas e práticas de educação ambiental e identificar elementos retóricos que têm sido utilizados na construção de sentidos sobre a temática ambiental e o processo educativo.

\section{Procedimentos de pesquisa}

Os diferentes projetos que vêm sendo desenvolvidos pelo grupo procuram centrar as suas análises em diferentes níveis a partir dos quais podemos identificar tendências e perspectivas da temática ambiental e sua relação com a educação ambiental, a saber:

- na análise de práticas diversificadas que têm sido desenvolvidas em contextos educacionais diversos tanto na tentativa de traçar um panorama do 
que vem sendo desenvolvido no Brasil como um todo como na possibilidade de aprofundamentos de experiências significativas a partir de "estudos de casos".

- depoimentos de educadores e educandos no que diz respeito aos significados e sentidos que têm sido construídos sobre aspectos da temática ambiental e sobre a educação ambiental nos contextos institucionais diversos e contextos não institucionais.

- aspectos relacionados com a temática ambiental e com propostas de educação ambiental presentes em materiais didáticos diversificados que têm servido de apoio ao trabalho dos educadores ambientais.

- produção da pesquisa relacionada com educação ambiental a partir das teses, dissertações e artigos publicados em eventos e periódicos. Para estas análises serão explorados os bancos de dados de teses e dissertações e o banco de periódicos da CAPES, além de outras bases de dados internacionais.

Estas possibilidades nos remetem a procedimentos de pesquisa vinculados à pesquisa documental, a realização de surveys e observação naturalística a partir de experiências significativas.

\section{Procedimentos de análise:}

Considerando os objetivos propostos e as questões que orientam as investigações do grupo, os procedimentos de coleta e de análises dos dados têm sido encaminhados a partir de perspectivas de análise diversas, dependendo do problema de investigação e das questões orientadoras dos diferentes projetos de pesquisa desenvolvidos. As pesquisas que têm uma perspectiva voltada para abordagens etnográficas têm se utilizado de técnicas de análise próprias dessas abordagens. Como referenciais para análise de dados, como já anteriormente mencionado temos feito o uso da "análise de conteúdo" (BARDIN, 1991; OLIVEIRA at al, 2003; Bauer e Gaskell, 2005) e estamos iniciando algumas tentativas de análises de processos de construção de sentidos tanto sobre a temática ambiental como sobre a educação ambiental (BRAIT, 2005; GOMES E NASCIMENTO, 2006).

\section{Referências}

ADORNO, T. W. HORKHEIMER, M. Dialética do Esclarecimento - fragmentos filosóficos, tradução, Guido Antonio de Almeida, Rio de janeiro: Jorge Zahar Ed., 1985.

BARDIN, L. Análise de Conteúdo. Tradução de Luís Antero Reto e Augusto Pinheiro. Lisboa: Edições 70, 1991.

BAUER, M. W.; Gaskell, G. Pesquisa qualitativa com texto, imagem e som: um manual prático. Petrópolis: Vozes, 2002.

BORNHEIM, G. Filosofia e Política Ecológica. Revista Filosófica Brasileira. 2(1): 16 - 24, 1985. 
BORNHEIM, G. A Temática Ambiental na Sociedade Contemporânea. Educação: Teoria e Prática, v. 9, n. 16, p. 1 - 9, jan-jun, 2001, jul-dez-2001.

BRAIT, B. Bakhtin, dialogismo e construção do sentido. Campinas: Edit. da UNICAMP, 2005.

CURY, C. R. J. Educação e contradição: elementos metodológicos para uma teoria crítica do fenômeno educativo. São Paulo: Cortez/Autores Associados, 1985.

GOMES, R.; NASCIMENTO, E. F. A produção do conhecimento da saúde pública sobre a relação homem-saúde: uma revisão bibliográfica. Cad. Saúde Pública, v. 22, n. 5, p. 901-911, 2006.

LATOUR, B. Políticas da natureza: como fazer ciência na democracia. Bauru: EDUSC. 2004.

LEFF, H. Epistemologia Ambiental. São Paulo: Cortez, 2002.

SEVERINO, A. J. Educação, Sujeito e História. São Paulo: Olho d’Água, 2001

OLIVERIA, E.; ENS, R. T.; ANDRADE, D. B. S. F.; MUSSIS, C. R. Análise de conteúdo e pesquisa na área da educação. Revista Diálogo Educacional, v. 4, n.9, p.1127, maio/ago. 2003.

Artigo recebido em 20/08/2010 - a aprovado em 17/12/2010 